\title{
Plano de gerenciamento de resíduos sólidos da construção civil: um panorama de análise a partir da Resolução 307 do CONAMA
}

\author{
RESUMO
}

Murillo Vetroni Barros murillo.vetroni@gmail.com Universidade Tecnológica Federal do Paraná (UTFPR), Ponta Grossa, Paraná, Brasil
A participação da construção civil no Produto Interno Bruto (PIB) brasileiro tem apresentado positivo crescimento nos últimos anos, entretanto, a geração de resíduos provido deste setor passou a ser tema e discussão de um problema ambiental, ou seja, a destinação de resíduos sólidos proveniente da construção civil. Métodos de reaproveitamento, reutilização, reciclagem têm sido debatido junto ao meio técnico, procurando medidas para minimizar os impactos ambientais causados pelos resíduos. Entretanto, ainda existem lacunas onde haja a aplicação de leis por parte de políticas públicas para esse real problema enfrentado no Brasil atualmente. A partir da Resolução 307/2002 do Conselho Nacional do Meio Ambiente (CONAMA) e da Política Nacional de Resíduos Sólidos (PNRS), o poder público municipal passou a ser responsável por estabelecer ações para o gerenciamento dos resíduos de construção de obra e as empresas de construção civil para destinação final correta dos resíduos. A resolução foi instituída visando minimizar os impactos ambientais, sociais e econômicos causados pela deposição irregular. Com o intuito de identificar as potencialidades e fragilidades do processo de reciclagem de resíduos da construção, foi realizado o presente estudo com os objetivos de expor a necessidade da implantação de um Plano de Gerenciamento de Resíduos da Construção Civil (PGRCC); relatar as recomendações da Resolução 307 do CONAMA; e, apresentar um estudo de caso realizado em um canteiro de obras. A pesquisa é classificada como exploratória, onde aborda os resíduos sólidos provenientes da construção civil. Como resultados, a contribuição com o meio técnico a respeito da importância da correta destinação dos resíduos de construção e demolição e seus impactos, causados pela sua destinação inadequada. Além disso, o estudo contribui para o conhecimento e a tomada de decisão de empresas no ramo da construção civil.

PALAVRAS-CHAVE: Construção Civil. Valorização de Resíduos. Sustentabilidade. Impacto Ambiental. 


\section{INTRODUÇÃO}

A problemática do lixo não é um tema que deu início a discussão recentemente, essa questão vem sendo discutido desde o século passado. Empresas, construtoras e organizações, de um modo geral, veem diminuindo o potencial poluidor em suas emissões e descartes, mesmo assim, esses processos no Brasil ainda acontecem lentamente. Os resíduos, seja ele doméstico, industrial, hospitalar ou provido da construção civil são produzidos em todos os estágios pelas atividades humanas.

Os resíduos perigosos rejeitados, sobretudo pela construção civil, são preocupantes, pois, quando descartados incorretamente, tornam-se uma grave ameaça ao meio ambiente. Para Prado Filho e Sobreira (2007), a conservação do meio ambiente tem sido tema de discussão mundialmente, já que os recursos naturais são finitos e a natureza não consegue absorver a produção exorbitante de resíduos gerados pela sociedade. Tal geração é reflexo do crescimento populacional, mudança de hábitos e intenso do consumo.

Na visão de Paschoalin Filho e Graudenz (2012), o aumento do setor da construção, tem alavancado o atual panorama econômico e a necessidade de atender ao déficit habitacional no Brasil, causando significativos impactos ambientais, seja pelo aumento da demanda por matéria-prima ou pela geração de resíduos. Já Farias, Fucale e Gusmão (2016), indicam que o setor da construção civil é considerado um dos mais importantes na economia de um país, entretanto, com a geração dos resíduos, provocam alterações no meio ambiente. Esses problemas ambientais começam desde a extração da matéria-prima até a destinação final dos resíduos.

Portanto, os objetivos deste trabalho é expor a necessidade da implantação de um Plano de Gerenciamento de Resíduos da Construção Civil (PGRCC); relatar as recomendações da Resolução 307 do Conselho Nacional do Meio Ambiente (CONAMA); e, apresentar um estudo de caso realizado em um canteiro de obras.

\section{REFERENCIAL TEÓRICO}

A seguir, é apresentada a fundamentação teórica necessária para compreender os objetivos do presente estudo.

\section{LEGISTAÇ̃̃O NACIONAL}

A construção civil é ponto essencial no crescimento de qualquer país, visto que é necessária a construção de empreendimentos tanto residenciais, comercias e industriais para o desenvolvimento. Para Paschoalin Filho et al. (2017), as empresas precisam possuir uma fase de execução do projeto de construção, que podem ser implementados no Sistemas de Gestão Ambiental (SGA) e no Sistemas de Gestão de Qualidade (SGQ), constituído de ferramentas que as permitem estabelecerem uma melhoria contínua do seu desempenho ambiental, de modo que, reduza seus potenciais impactos ambientais em suas atividades. Completam os autores que este desempenho é visto com importância para os olhos de stakeholders e o público consumidor. Portanto, para que os volumes de Resíduos de Construção Civil (RCC) gerados sejam minimizados, bem como os potenciais 
impactos ambientais causados pelas reformas e construções, os gestores/empresários devem se preocupar, cada vez mais, com a adoção de SGA e SGQ em seus empreendimentos.

Amadei et al. (2012) apontam que, além dos impactos gerados durante a extração das matérias-primas naturais, também ocorrem aqueles impactos causados pelos resíduos gerados nas etapas posteriores, ou seja, na construção, demolição, manutenção, adequação e reforma dos edifícios. Deste modo, é preciso considerar o descarte correto dos resíduos de construção civil em todo o ciclo de vida da construção, isto é, desde o pré-projeto, projeto, terraplanagem, até etapas finais como pintura, arborização, pavimentação final.

Os principais impactos sanitários e ambientais relacionados aos Resíduos de Construção e Demolição (RCDs) estão associados às deposições irregulares, acarretando no comprometimento do ambiente urbano, como paisagem, tráfego de pedestres e veículos e drenagem pluvial (PASCHOALIN FILHO e GRAUDENZ, 2012). Finalizam os autores que os RCDs dispostos inadequadamente podem poluir o solo, degradam paisagens urbanas e constituem uma severa ameaça à saúde coletiva.

De acordo com a Política Nacional de Resíduos Sólidos (PNRS, 2010), estão sujeitos à elaboração de um Plano de Gerenciamento de Resíduos Sólidos (PGRS) aqueles que geram resíduos domiciliares, de limpeza urbana, resíduos industriais (provenientes do processo produtivo e suas instalações) e também resíduos de mineração. Estão sujeitos ainda os que geram resíduos perigosos, resíduos de construção civil, e responsáveis por atividades agrossilvopastoris. Já no âmbito municipal, estão inclusos todos os citados acima e ainda os geradores de serviços de saúde (exceto o que realize atendimento hospitalar ou que gere volume acima de 30 litros/semana), além dos geradores de resíduos dos serviços públicos de abastecimento de água, esgotamento sanitário e manejo de águas pluviais.

Foi em 5 de Julho de 2002 que houve a publicação da resolução 307 do CONAMA, e a partir disso os geradores começaram a ser responsáveis pelos resíduos gerados. Essa resolução foi alterada pelas 348, de 2004, 431 de 2011 e 448 de 2012, estabelecendo diretrizes, critérios e procedimentos para a gestão dos resíduos da construção civil com objetivo de minimizar os impactos ambientais.

De acordo com a Resolução do CONAMA (2002), os RCDs recebem a seguinte denominação:

Resíduos da construção civil: são os provenientes de construções, reformas, reparo de demolições de obras de construção civil, e os resultantes da preparação e da escavação de terrenos, tais como: tijolos, blocos cerâmicos, concreto em geral, solos, rochas, metais, resinas, colas, tintas, madeiras e compensados, forros, argamassa, gesso, telhas, pavimento asfáltico, vidros, plásticos, tubulações, fiação elétrica etc., comumente chamados de entulhos de obras, caliça ou metralha.

Além disso, a Resolução do CONAMA (2002) apresenta algumas características quanto a sua classificação, tais como, quanto às características físicas, composição química e quanto a origem, cujas estão discorridas abaixo: 
$\rightarrow$ Quanto às características físicas:

$\checkmark$ Seco: papéis, plásticos, metais, couros tratados, tecidos, vidros, madeiras, guardanapos e tolhas de papel, pontas de cigarro, isopor, lâmpadas, parafina, cerâmicas, porcelana, espumas, cortiças.

$\checkmark$ Molhado: restos de comida, cascas e bagaços de frutas e verduras, ovos, legumes, alimentos estragados, etc.

$\rightarrow$ Quanto à composição química:

$\checkmark$ Orgânico: é composto por pó de café e chá, cabelos, restos de alimentos, cascas e bagaços de frutas e verduras, ovos, legumes, alimentos estragados, ossos, aparas e podas de jardim.

$\checkmark$ Inorgânico: composto por produtos manufaturados como plásticos, vidros, borrachas, tecidos, metais (alumínio, ferro, etc.), tecidos, isopor, lâmpadas, velas, parafina, cerâmicas, porcelana, espumas, cortiças, etc.

$\rightarrow$ Quanto à origem:

$\checkmark$ Domiciliar: originado da vida diária das residências, constituído por restos de alimentos (tais como cascas de frutas, verduras, etc.), produtos deteriorados, jornais, revistas, garrafas, embalagens em geral, papel higiênico, fraldas descartáveis e uma grande diversidade de outros itens. Pode conter alguns resíduos tóxicos.

$\checkmark$ Comercial: originado dos diversos estabelecimentos comerciais e de serviços, tais como supermercados, estabelecimentos bancários, lojas, bares, restaurantes, etc.

$\checkmark$ Serviços públicos: originados dos serviços de limpeza urbana, incluindo todos os resíduos de varrição das vias públicas, limpeza de praias, galerias, córregos, restos de podas de plantas, limpeza de feiras livres, etc, constituído por restos de vegetais diversos, embalagens, etc

$\checkmark$ Hospitalar: descartados por hospitais, farmácias, clínicas veterinárias (algodão, seringas, agulhas, restos de remédios, luvas, curativos, sangue coagulado, órgãos e tecidos removidos, meios de cultura e animais utilizados em testes, resina sintética, filmes fotográficos de raios-X). Em função de suas características, merece um cuidado especial em seu acondicionamento, manipulação e disposição final. Deve ser incinerado e os resíduos levados para aterro sanitário.

$\checkmark$ Portos, aeroportos, terminais rodoviários e ferroviários: resíduos sépticos, ou seja, que contêm ou potencialmente podem conter germes patogênicos. Basicamente originam-se de material de higiene pessoal e restos de alimentos, que podem hospedar doenças provenientes de outras cidades, estados e países.

$\checkmark$ Industrial: originado nas atividades dos diversos ramos da indústria, tais como: o metalúrgico, o químico, o petroquímico, o de papelaria, da indústria alimentícia, etc. O lixo industrial é bastante variado, podendo ser representado por cinzas, lodos, óleos, resíduos alcalinos ou ácidos, plásticos, papel, madeira, fibras, borracha, metal, escórias, 
vidros, cerâmicas. Nesta categoria, inclui-se grande quantidade de lixo tóxico. Esse tipo de lixo necessita de tratamento especial pelo seu potencial de envenenamento.

$\checkmark$ Radioativo: resíduos provenientes da atividade nuclear (resíduos de atividades com urânio, césio, tório, radônio, cobalto), que devem ser manuseados apenas com equipamentos e técnicas adequados.

$\checkmark$ Agrícola: resíduos sólidos das atividades agrícola e pecuária, como embalagens de adubos, defensivos agrícolas, ração, restos de colheita, etc. O lixo proveniente de pesticidas é considerado tóxico e necessita de tratamento especial.

$\checkmark$ Entulho: resíduos da construção civil: demolições e restos de obras, solos de escavações. O entulho é geralmente um material inerte, passível de reaproveitamento.

Uma ferramenta importante empregado atualmente na problemática ambiental é a implantação de programas de gestão desse resíduo. Um mecanismo criado para tal finalidade foi a Resolução 307 (CONAMA, 2002), que define, para a construção civil, quatro classes de resíduos, que deverão ter tratamentos distintos:

$\rightarrow$ I. Resíduos Classe A: são os resíduos reutilizáveis ou recicláveis como agregados, quando inertes, tais como:

$\checkmark$ de construção, demolição, reformas, e reparos de pavimentação e de outras obras de infraestrutura, inclusive solos e rochas provenientes de escavação e terraplanagem;

$\checkmark$ de construção, demolição, reformas e reparos de edificações: componentes cerâmicos (tijolos, blocos, telhas, placas de revestimento), argamassa e concreto;

$\checkmark$ de processo de fabricação ou demolição de peças pré-moldadas em concreto (blocos, tubos, meios fios) produzido nos canteiros de obras.

$\rightarrow$ II. Resíduos Classe B: são resíduos recicláveis para outras destinações desde que não contaminados, como por exemplo, plásticos (embalagens, PVC de instalações), papeis e papelões (embalagens de argamassa, embalagens em geral, documentos), metais (perfis metálicos, tubos de ferro galvanizado, marmitex de alumínio, aço, esquadrias de alumínio, grades de ferro, resíduos de ferro em geral, fios de cobre, latas), madeiras (forma, madeiras em geral), gesso e vidros.

$\rightarrow$ III. Resíduos Classe C: são os resíduos não perigosos para os quais não foram desenvolvidas tecnologias ou aplicações economicamente viáveis que permitam a sua reciclagem ou recuperação. Exemplo são as estopas, isopor, lixas, mantas alfáltica, massa de vidro, sacos de cimento, tubos de poliuretano.

$\rightarrow$ IV. Resíduos Classe D: são os resíduos perigosos oriundos do processo de construção, tais como tintas, solventes, óleos e outros ou aqueles contaminados oriundos de demolições, reformas e reparos de clínicas radiológicas, instalações industriais e outros, bem como telhas e demais objetos e materiais que contenham amianto ou outros produtos nocivos à saúde. Exemplo são as tintas, solventes, óleos, resíduos de clinicas radiológicas, latas e sobras de aditivos e 
desmoldantes, telhas e outros materiais de amianto, tintas e sobras de material de pintura.

Para as atividades de gerenciamento de resíduos, a NBR 10.004 (ABNT, 2004a) é uma ferramenta muito importante, pois pode ser aplicada por organizações e órgãos fiscalizadores. A partir da classificação firmada pela Norma, o gerador de um resíduo pode identificar o potencial de risco do mesmo, além disso, podendo identificar as melhores alternativas para destinação final, reuso e/ou reciclagem do resíduo. Esta versão da norma classifica os resíduos em três classes distintas: classe I (perigosos), classe II (não-inertes) e classe III (inertes).

$\rightarrow$ Classe I - Resíduos perigosos: aqueles que, em razão de suas características de inflamabilidade, corrosividade, reatividade, toxicidade, patogenicidade, carcinogenicidade, teratogenicidade e mutagenicidade, apresentam significativo risco à saúde pública ou à qualidade ambiental, de acordo com lei, regulamento ou norma técnica;

$\rightarrow$ Classe II - Resíduos não-inertes: são os resíduos que não apresentam periculosidade, entretanto, não são inertes, podendo apresentar propriedades tais como, combustibilidade, biodegradabilidade ou solubilidade em água. São basicamente os resíduos com as características do lixo doméstico;

$\rightarrow$ Classe III - Resíduos inertes: são aqueles que ao serem submetidos aos testes de solubilização (NBR 10.007 - ABNT, 2004b) não apresentam nenhum de seus constituintes solubilizados em concentrações superiores aos padrões de portabilidade da água.

Nessa classificação, os entulhos, provenientes de construção e/ou reformas são resíduos que não se degradam ou não se decompõem quando dispostos no solo (eles se degradam muito lentamente, como pedras e areias).

Em relação aos resíduos sólidos gerados em construção civil, ou seja, provenientes do entulho enquadra-se na classe III, como resíduos inertes. Além disso, o responsável pela destinação final desse resíduo é o próprio gerador.

No gerenciamento de resíduos sólidos todas as soluções a serem adotadas (alternativas tecnológicas, valorização, tratamento) deverão considerar três fatores básicos (PEREIRA, CASTILHOS e OLIVEIRA, 1993):
$\checkmark$ Ser uma solução pautada em princípios ecológicos que contemple a minimização da geração de resíduos a maximização da reciclagem e reutilização como forma de diminuir a pressão sobre o meio ambiente;
$\checkmark$ Estar coerente com os objetivos sanitários;
$\checkmark$ Incentivar a participação de todos os envolvidos.

\section{PROCEDIMENTOS METODOLÓGICOS}

A pesquisa consistiu de um levantamento bibliográfico, visando com isso um maior entendimento sobre o problema, bem como buscar identificar as principais aplicações e destinações dadas para os resíduos da construção civil. Os itens 
componentes desta ferramenta foram baseados nas recomendações encontradas na Resolução 307/2002 do CONAMA.

\section{PROCEDIMENTOS DE COLETA DE DADOS}

A pesquisa que gerou este trabalho foi caracterizada por uma abordagem qualitativa, com objetivos exploratórios, como o levantamento bibliográfico narrativo e a revisão bibliográfica sistemática. Tal abordagem permitiu aprofundar o entendimento sobre os principais conceitos e princípios de resíduos sólidos na construção civil. foram:

Em relação ao estudo da obra visitada, as fontes de informação utilizadas

$\checkmark$ Observação direta: Foram realizadas visitas técnicas no canteiro de obras, de forma que o pesquisador pudesse observar a conformidade dos processos desenvolvidos no local. Observou-se primeiramente, a presença de itens físicos, tais como disposição de baias, locais para triagem etc. Por último, foram analisados os registros, documentações;

$\checkmark$ Pesquisa Documental: Foram consultados os seguintes documentos da obra: PGRCC - o qual é composto pelos procedimentos, ferramentas de gestão e manejo dos resíduos gerados, tais como presença de estações de triagem, destinação dos resíduos etc.;

$\checkmark$ Foram realizadas entrevistas com os engenheiros e os mestres de obras responsáveis pela obra pesquisada para entender melhor todo o processo.

A presente obra visitada localiza-se na cidade de Curitiba/PR, onde foram relatados itens relacionado à disposição dos resíduos provenientes da construção civil, além das oportunidades de redução, reutilização e reciclagem de resíduos, assim como definida a melhor forma de disposição final para os resíduos remanescentes.

O local onde foram gerados os resultados é um condomínio residencial (em fase de acabamento), feito em alvenaria estrutural. A área total do terreno é de $10.870,13 \mathrm{~m}^{2}$. Contando com $6.975,68 \mathrm{~m}^{2}$ de área construída. A obra apresenta 4 funcionários fixos e aproximadamente 20 funcionários flutuantes (empresas terceirizadas).

\section{ESTUDO DE CASO NO CANTEIRO DE OBRAS}

A cidade de Curitiba, capital do estado do Paraná, passa por um crescente desenvolvimento no setor da construção civil. Nas últimas décadas a cidade verticalizou-se aceleradamente, tanto em regiões centrais, como nos bairros, bem como o acúmulo dos resíduos desta atividade. A região Sul é a terceira região brasileira que mais gera resíduos de construção civil (ABRELPE, 2014), ficando atrás apenas da região Sudeste e Nordeste. Entretanto, há um grande problema na geração desses resíduos, pois ocupam grandes espaços físicos. Como solução desse problema, há o incentivo de práticas como a reciclagem. 
A construtora tem o conhecimento da Resolução 307 do CONAMA, a qual é aplicada com práticas como o reaproveitamento de reboco como areia e há o envolvimento dos funcionários, os quais recolhem o material não utilizado diariamente.

Para o canteiro de obra visitado, a maior parte dos resíduos estão concentrados nas Classes $A$ e $B$, que são considerados resíduos recicláveis. Entretanto, a mistura dos resíduos de classe A gera o resíduo misto. Deste modo, uma das soluções sugerida pelo autor foi de fazer a reciclagem de matéria-prima para a produção de outros materiais utilizáveis construção civil, como por exemplo, o concreto e argamassa. Neste caso, os resíduos mais utilizados para a produção de concretos e argamassas são: cerâmica, gesso, resíduo misto (resíduos de concreto e cerâmicos) e o granito.

\section{TRIAGEM DOS RESÍDUOS}

O processo de triagem tem como objetivo a separação do PGRCC de acordo com a classe, evitando a mistura de resíduos, o que poderia prejudicar a qualidade final dos mesmos, assim como a destinação final. Deste modo, o Quadro 1 apresenta as possíveis fontes de geração de resíduos sólidos provenientes da obra, de acordo com as fontes primária e sua respectiva abrangência.

Quadro 1 - Fontes de geração de resíduos e sua abrangência

\begin{tabular}{|l|l|}
\hline \multicolumn{1}{|c|}{ Fonte Primária } & \multicolumn{1}{c|}{ Abrangência } \\
\hline Demolição & Restos de materiais de construção civil \\
\hline Serviços gerais/administração & Papel, plástico \\
\hline Instalação do canteiro de obras & Madeira, plástico \\
\hline Fundação & Movimentação de terra \\
\hline Estrutura & Madeira, prego, papel \\
\hline Fechamento de alvenaria & Argamassa, blocos \\
\hline Revestimento & Gesso, revestimento cerâmico, madeira \\
\hline Instalações & Plástico, cobre, alumínio \\
\hline Pintura & Tintas \\
\hline
\end{tabular}

Fonte: Dados da empresa (2017).

O processo de triagem dos resíduos é representado pela separação na fonte, ou seja, no ponto de geração dos resíduos. Para isso, foram distribuídos em ilhas de coleta, coletores devidamente identificados conforme o tipo de resíduo, desta forma, facilita a remoção e o encaminhamento ao Depósito Intermediário de Resíduos (DIR) e este para a destinação final adequada.

A formação e a localização das ilhas de coleta são variáveis de acordo com os tipos de resíduos gerados em cada etapa da obra. A separação é realizada pelos próprios funcionários da obra, em sua área de trabalho, assim como o acondicionamento nos coletores dispostos na ilha de coleta mais próxima. 


\section{COLETA INTERNA DE RESÍDUOS}

Os resíduos da área interna são retirados através dos próprios colaboradores conforme a necessidade, ao final de cada dia, um encarregado faz uma inspeção nas ilhas de coleta e recolhe os resíduos conforme a necessidade, e encaminhaos ao DIR em baias específicas e/ou diretamente as caçambas, até a retirada pela empresa transportadora e/ou receptora.

A empresa possui um sistema próprio, onde todos os resíduos, inclusive aqueles que não passam pelo DIR serão controlados em função do volume, pelo responsável da remoção antes da retirada, registrando no formulário de controle de destinação o tipo de resíduo e respectiva quantidade ou volume.

\section{MANUSEIO DOS RESÍDUOS}

O manuseio dos resíduos pode ser prejudicial a saúde do trabalhador, por isso é realizado com o Equipamento de Proteção Individual (EPI) adequado para cada tipo de resíduo conforme o Quadro 2, classificado de acordo com cada classe o EPI correspondente.

Quadro 2 - Uso de EPIs de acordo com as Classes dos resíduos

\begin{tabular}{|c|l|}
\hline Classe & EPI \\
\hline A & Luvas, sapatos, óculos de proteção, máscara facial, uniforme \\
\hline B & Luvas, sapatos, óculos de proteção, máscara facial, uniforme \\
\hline C & Luvas, sapatos, óculos de proteção, máscara facial, uniforme \\
\hline D & Luvas, sapatos, óculos de proteção, máscara facial, uniforme \\
\hline
\end{tabular}

Fonte: Dados da empresa (2017).

Portanto, o mestre de obras deve estar informado sobre a existência das possíveis situações de manuseio perigoso para fornecer as orientações necessárias aos demais colaboradores. Os EPIs considerados básicos para qualquer manuseio dos resíduos sólidos são: luvas, sapato de segurança, óculos de proteção, máscara facial e uniforme.

\section{ACONDICIONAMENTO DOS RESÍDUOS}

Os RCC são acondicionados utilizando coletores devidamente identificados, conforme o tipo de resíduos e de acordo com o Quadro 3.

Quadro 3 - Identificação dos resíduos

\begin{tabular}{|c|c|c|}
\hline Resíduo & Cor do coletor ou etiqueta & Identificação \\
\hline Papel & Azul & Papel/papelão \\
\hline Plástico & Vermelho & Plástico \\
\hline Metal & Amarelo & Metal \\
\hline Rejeito & Cinza & Rejeito \\
\hline Vidro & Verde & Vidro \\
\hline Madeira & Preto & Madeira \\
\hline Resíduos de saúde & Branco & Infectante \\
\hline Resíduos perigosos & Laranja & Perigoso \\
\hline
\end{tabular}




\begin{tabular}{|c|c|c|}
\hline Resíduos orgânicos & Marrom & Orgânico \\
\hline Resíduos de concreto & Preto & Concreto \\
\hline Resíduos de cerâmica & Preto & Cerâmica \\
\hline
\end{tabular}

Fonte: Dados da empresa (2017).

Desta foram, os resíduos são separados em recicláveis (papel, papelão, plástico, metal, madeira), não recicláveis (rejeito, concreto, cerâmica), perigosos (resíduos perigosos, infectantes), não perigosos, orgânico (resíduos orgânicos).

Quando há a presença de remoção de camada vegetal, supressão de árvores e destoca, tais resíduos são segregados pelos próprios funcionários da obra e acondicionados em local específico, como baias identificadas.

Já para os resíduos, tais como, lâmpadas e baterias (quando apresentadas) são gerenciadas de acordo com a legislação ambiental e normas técnicas pertinentes, com destinação preferencial à reciclagem e a logística reversa.

A segregação de resíduos é realizada em tambores ou baias, com o treinamento do pessoal. A identificação e quantificação dos resíduos são feitas com o auxílio de planilhas computacionais, as quais geram, também, o percentual de economia gerada pela própria empresa. Tal segregação é realizada pelos colaboradores da obra no final do dia.

A empresa conta com áreas para depósitos temporários dos resíduos da Classe $A$, os quais ficam em baias. A contribuição para a reciclagem de resíduos nos canteiros de obras conta com a união e conscientização de toda a equipe da empresa. A construtora se beneficia da mobilização de toda sua equipe, bem como dos seus funcionários, com ações como campanhas educativas, envolvendo palestras, treinamento do pessoal.

\section{ARMAZENAGEM DOS RESÍDUOS}

$\mathrm{Na}$ etapa de armazenagem dos resíduos é feito no DIR, o qual tem condições para armazenar todos os tipos de resíduos gerados. Os resíduos classificados como não perigosos (Classe A, B e C), onde as características seguidas pela empresa são:

\footnotetext{
$\checkmark$ Apresenta a divisão com baias identificadas;

$\checkmark$ Realiza a armazenar direta do resíduo ou dos coletores;

$\checkmark$ Apresenta piso e cobertura adequada;

$\checkmark$ Possui a identificação com acesso restrito a pessoas autorizadas.
}

Já os resíduos classificados como perigosos (Classe D) apresentam as características de:

$\checkmark$ São armazenados em áreas cobertas, bem ventiladas e sobre base impermeabilizada;

$\checkmark$ Possui a existência de um sistema de drenagem no caso de vazamento; 
$\checkmark$ Havendo a possibilidade de vazamento de óleo, há um separador de água e óleo;

$\checkmark$ Apresenta rótulos para facilitar a identificação;

$\checkmark$ Há recipientes em boas condições de uso;

$\checkmark$ Nota-se que os recipientes estão sempre fechados;

$\checkmark$ Percebe-se que o manuseio ocorre com cautela, de modo que não haja vazamento ou derramamento do material.

\section{TRANSPORTE DOS RESÍDUOS}

A transportadora (empresa terceirizada é identificada por classe de resíduo, bem como é verificada a situação em função da legislação pertinente). Ademais, o transporte é acompanhado do Manifesto de Transporte de Resíduos (MTR).

As empresas receptoras de resíduos sólidos e/ou rejeitos, quando realizam a coleta de qualquer material da obra, fazem a emissão do Certificado de Destinação de Resíduos (CDR), o qual deve conter a identificação própria, identificação do receptor, a caracterização do resíduo ou rejeito, local, data e assinaturas.

\section{CONCLUSÕES}

Portanto, este trabalho expôs a necessidade da implantação de um PGRCC, acompanhado das recomendações da Resolução 307 do CONAMA, além de apresentar um estudo desenvolvido em um canteiro de obras.

O desenvolvimento da construção civil no país apresenta um crescimento exponencial nos últimos anos, acarretando na geração de resíduos. Com o crescente número de materiais, provenientes da construção civil identificado como perigosos e a geração desses resíduos em alto volume têm exigido soluções mais eficazes e forte investimento pelos geradores e sociedade da forma geral.

De acordo com os resultados obtidos e as análises efetuadas, pode-se concluir que a empresa, vista no estudo, possui ferramentas de gestão e manejo de seus resíduos, entretanto somente voltadas para o descarte destes. Salientase que, apesar de não ser obrigatória, de acordo com a Resolução CONAMA $307 / 2002$, a reciclagem e o reuso dos resíduos nos canteiros é fortemente sugerida, de forma a mitigar os impactos ambientais causados pelas obras. No entanto, o PGRCC, ainda não é integralmente praticado. Isso pode ser observado pela falta de conscientização da construtora.

A tendência futura nas construtoras é assumir o princípio de quem gera o resíduo é responsável por sua separação, limpeza e armazenamento bem como destinação final adequada. Outras etapas do PGRS, como limpeza e armazenamento temporário, segregação ou coleta seletiva, transporte interno, transporte e destino, tendem a ser rotineiras, num futuro próximo em construtoras.

Empresa que recorrem a esses tratamentos terão amplos benefícios ao implantar, no seu dia-a-dia, as etapas e práticas sugeridas no plano de 
gerenciamento de resíduos sólidos, reduzindo, assim, seus gastos com técnicas de tratamentos de resíduos, com energia elétrica, e inclusive com equipe responsável. Diante de tais sugestões e comentários, espera-se favorecer tanto esta construtora, como outras interessadas em melhorar sua produção e reduzir gastos, a médio e longo prazo, assim como ajudar a sociedade e sua população como um todo.

Este trabalho contribui para que o meio acadêmico, em diversas áreas como Administração, Engenharia, Arquitetura tenham interesse em Construções Sustentáveis, e tome conhecimento sobre a legislação focada na gestão de RCC, além das certificações e as melhores práticas aplicadas pelas construtoras para que sejam reduzidos os impactos ambientais de obras de construção.

O presente estudo é de grande utilidade para empresas (construtoras) que desejam melhorar o gerenciamento dos seus resíduos. Tem-se que a preocupação ambiental é cada dia maior em todos os setores da sociedade, o respeito que determinada empresa possui sobre o meio ambiente pode gerar aceitação pública, além da vantagem competitiva. Portanto, as tecnologias de fim de tubo não são as melhores opções de disposição final de resíduos e, sim, a prevenção.

Sugere-se que futuros trabalhos pesquisem de que maneira outras construtoras estão praticando a gestão dos RCC, bem como garantindo a qualidade das construções de acordo com a legislação vigente e as certificações existentes. Além disso, a elaboração de outros estudos na cidade de Curitiba ou em outras localidades poderá trazer novos conhecimentos e comparações. 


\title{
Solid waste management plan for construction: a panorama of analysis based on Resolution 307 of CONAMA
}

\author{
ABSTRACT
}

The participation of civil construction in the Brazilian Gross Domestic Product (GDP) has shown positive growth in recent years, however, the generation of waste provided by this sector has become the theme and discussion of an environmental problem, that is, the destination of solid waste from construction. Methods of reuse, reuse, recycling have been discussed with the technical environment, seeking measures to minimize the environmental impacts caused by waste. However, there are still gaps where there is the application of laws by public policies for this real problem faced in Brazil today. As of Resolution 307/2002 of the National Environmental Council (CONAMA) and the National Solid Waste Policy (PNRS), the municipal public authority became responsible for establishing actions for the management of construction waste and companies for the final disposal of waste. The resolution was instituted to minimize the environmental, social and economic impacts caused by irregular deposition. In order to identify the potentialities and weaknesses of the construction waste recycling process, the present study was carried out with the objective of exposing the need to implement a Civil Construction Waste Management Plan (PGRCC); to report on the recommendations of CONAMA Resolution 307; and, present a case study carried out at a construction site. The research is classified as exploratory, where it addresses solid waste from construction. As a result, the contribution with the technical environment regarding the importance of the correct destination of construction and demolition wastes and their impacts, caused by their inadequate disposal. In addition, the study contributes to the knowledge and decision making of companies in the construction industry.

KEYWORDS: Construction. Waste valorization. Sustainability. Environmental impact. 


\section{REFERÊNCIAS}

ABNT - Associação Brasileira de Normas Técnicas. Classificação de Resíduos Sólidos, Rio de Janeiro. NBR 10.004, 2004a.

ABNT - Associação Brasileira de Normas Técnicas. Procedimentos para Amostragem de Resíduos. Rio de Janeiro. NBR 10.007, 2004b.

ABRELPE - Associação Brasileira de Limpeza Pública e Resíduos Especiais. Panorama dos resíduos sólidos no Brasil 2014. Abrelpe, 2014. Disponível em: <http://www.abrelpe.org.br/Panorama/panorama2014.pdf>. Acesso em 02 set. 2017.

AMADEI, D. I. B.; PEREIRA, J. A.; SOUZA, R. A.; MENEGUETTI, K. S. A questão dos resíduos de construção civil: um breve estado da arte. Revista Nupem, v. 3, n. 5, p. 185-199, 2012.

CONAMA - Conselho Nacional do Meio Ambiente. Resolução no. 307, de 05 de julho de 2002. Brasília. Diário Oficial da União, de 30 de Agosto de 2002, seção I, p. 17.241.

FARIAS, A.; FUCALE, S.; GUSMÃO, A. Diagnóstico de Gestão de Resíduos da Construção Civil no Município de Olinda. Revista de Engenharia e Pesquisa Aplicada, v. 2, n. 1, 2016.

PASCHOALIN FILHO, J. A.; BEZERRA, P. R. L; OLIVEIRA, L. R. G. J.; FARIA, A. C. Gerenciamento de Resíduos de Construção Civil em Edifícios Residenciais no Município de São Paulo. Environmental \& Social Management Journal/Revista de Gestão Social e Ambiental, v. 11, n. 1, 2017.

PASCHOALIN FILHO, J. A.; GRAUDENZ, G. S. Destinação Irregular de Resíduos de Construção e Demolição (RCD) e seus Impactos na Saúde Coletiva. Environmental \& Social Management Journal/Revista de Gestão Social e Ambiental, v. 6, n. 1, 2012.

PEREIRA, J. T.; CASTILHOS, A. B.; OLIVEIRA, S. M. L. Resíduos urbanos domiciliares: um paradoxo da sociedade moderna. Anais. In: Congresso Brasileiro de Engenharia Sanitária e Ambiental, 17. ABES, 1993. p. 311-19.

PNRS - Política Nacional de Resíduos Sólidos. PNRS Lei Brasileira № 12305/2010.

PRADO FILHO, J. F.; SOBREIRA, F. G. Desempenho operacional e ambiental de unidades de reciclagem e disposição final de resíduos sólidos domésticos 
financiadas pelo ICMS Ecológico de Minas Gerais. Engenharia Sanitária Ambiental. 12 (1), 52-61, 2007. crossref

Recebido: 02 set. 2017

Aprovado: 12 dez. 2017

DOI: $10.3895 /$ rgi.v13n4.7010

Como citar:

BARROS, M. V. Plano de gerenciamento de resíduos sólidos da construção civil: um panorama de análise a partir da Resolução 307 do CONAMA. R. Gest. Industr., Ponta Grossa, v. 13, n. 4, p. 139-153, out./dez. 2017. Disponível em: $\leq$ https://periodicos.utfpr.edu.br/rgi>. Acesso em: XXX.

Correspondência:

Murillo Vetroni Barros

Av. Monteiro Lobato s/n, Jardim Carvalho, Ponta Grossa, Paraná, Brasil.

Direito autoral: Este artigo está licenciado sob os termos da Licença Creative Commons-Atribuição 4.0

Internacional.

\section{(c) (1)}

